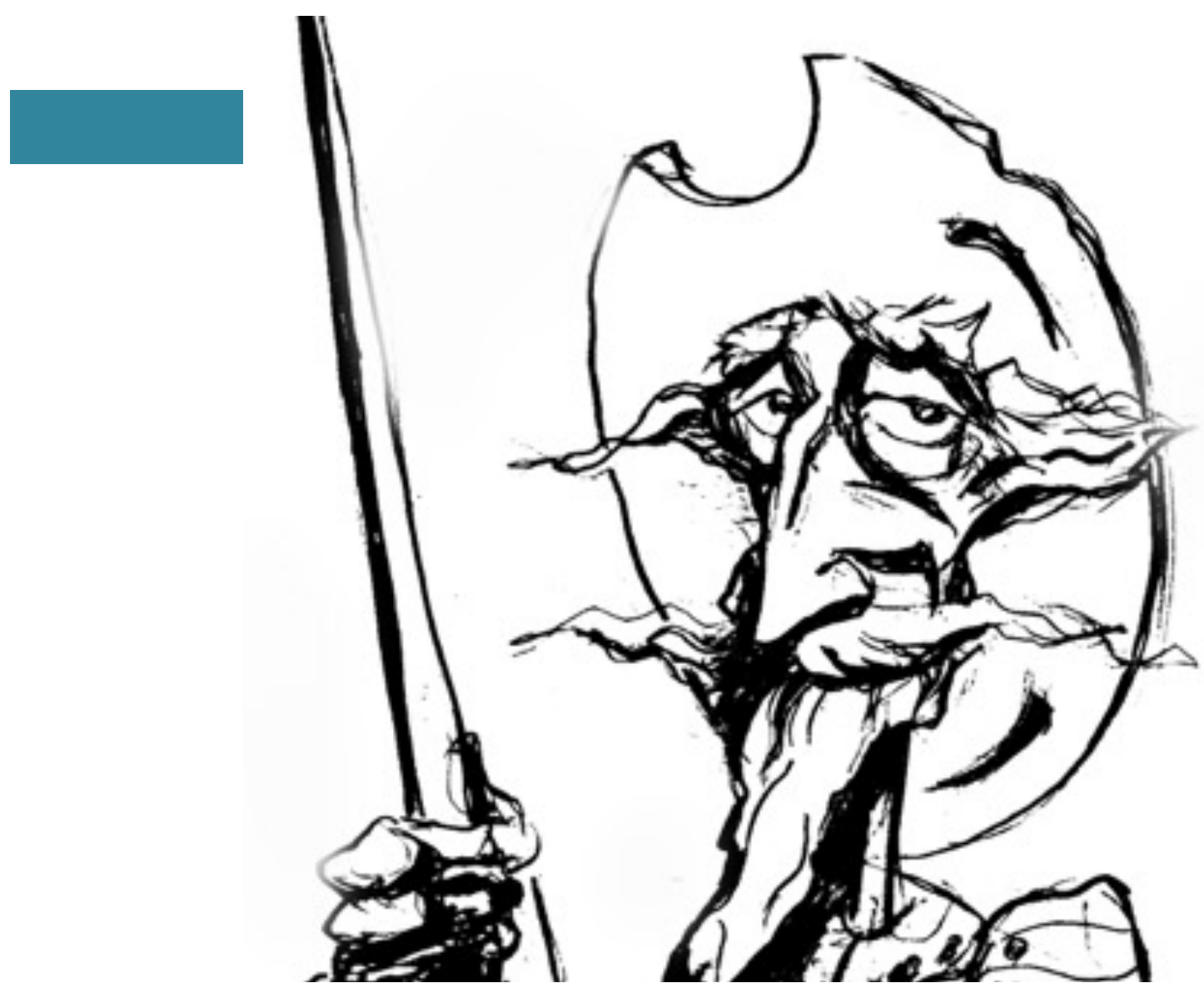

El encuentro con el Hombre, el Maestro y el Historiador

[Lucía Lionetti] 


\section{El encuentro con el Hombre, el Maestro y el Historiador}

The meeting with the Man, the Teacher and the Historian

LUCÍA LIONETTI

\section{Resumen}

En el presente escrito se pretende hacer un reconocimiento a Juan Carlos Garavaglia, a quien tanto le adeudamos. Los proyectos que emprendió de forma entusiasta y generosa, a lo largo de su trayecto personal y profesional, abrieron oportunidades para muchos de nosotros. En el caso particular de quien escribe estas líneas, tuvo la oportunidad de conocerlo cuando llegó a la UNCPBA con la recuperación de la democracia. Desde esos tiempos, cuando impulsó la creación del Instituto de Estudios Histórico-Sociales (IEHS), su labor en la docencia y en la investigación fue y es una fuente de inspiración permanente que ilumina el derrotero de mi propia investigación.

\section{Palabras Clave}

Juan Carlos Garavaglia - reconocimiento maestro - historiador

\begin{abstract}
This paper seeks to pay tribute to Juan Carlos Garavaglia, to whom we all owe so much. The projects that he pursued with enthusiasm and generosity meant opportunities for many of us. In my case, I had the chance of meeting him when he first arrived to the UNCPBA, during the recovery of democracy. Since then, when he drove the creation of the Instituto de Estudios Histórico-Sociales (IEHS), his work in teaching and research has been and still is a permanent source of inspiration that lights the course of my own research.
\end{abstract}

\section{Key words}

Juan Carlos Garavaglia - tribute - teacher historian

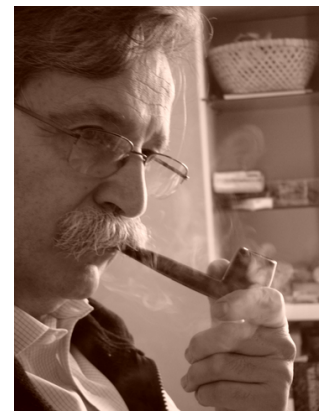

Recibido con pedido de publicación el 16 de septiembre de 2017 Aceptado para su publicación el 20 de octubre de 2017

Versión definitiva recibida el 30 de noviembre de 2017

Lucía Lionetti, Instituto de Estudios Histórico Sociales, Instituto de Geografía, Historia y Ciencias Sociales, Consejo Nacional de Investigaciones Científicas y Técnicas, Universidad Nacional del Centro de la Provincia de Buenos Aires, Argentina; e-mail: lionettilucia@gmail.com

Esta obra se publica bajo licencia Creative Commons. Atribución-NoComercial-CompartirIgual $\underline{\text { Internacional }}$

Lionetti, Lucía "El encuentro con el Hombre, el Maestro y el Historiador", Prohistoria, Año XX, núm. 28, Homenaje a Juan Carlos Garavaglia, dic. 2017, pp. 233-251.

Después de muchos intentos por escribir algunas líneas que estuvieran a la altura de lo que el Maestro Juan Carlos Garavaglia nos legó, tomé conciencia de lo infructuoso de la tarea. Nada de lo plasmado en estas erráticas líneas hace justicia a su condición humana y profesional. Asumo que este escrito, por la intensidad de la emoción, no refleja lo que significó este hombre entrañable, 
apasionado, afectuoso y sensible. El silencio de su ausencia tiene una estruendosa sonoridad cuando afloran los recuerdos que me remontan a ese tiempo pasado.

Si efectivamente, mis recuerdos me llevan a los años ochenta cuando, en el marco de la democratización de la Argentina, se inició la renovación de la carrera de Historia de la Facultad de Ciencias Humanas de la Universidad del Centro de la Provincia de Buenos Aires, de la ciudad de Tandil. Ese fue el contexto en el cual, durante el proceso de democratización de las universidades, con su consecuente renovación del elenco de su cuerpo docente, en nuestra casa de estudios, y en particular en el Departamento de Historia, un grupo de emprendedores docentes -muchos de los que eran portadores de la dolorosa experiencia de los exilios internos y externos- vieron que en Tandil todo estaba por hacerse y que era posible trabajar en conjunto con entusiastas estudiantes y jóvenes graduados en pos de un proyecto: la renovación en la producción del conocimiento histórico. La tarea era enorme pero entusiasmaba, sin embargo, no todo era tan auspicioso. El cambio implicaba abrir el juego a la dinámica de los concursos docentes y eso impactó en las relaciones personales de ese micro mundo de la Facultad de Humanidades. El fragor del cambio que la democratización abrazó, tuvo sus costos y hubo valentía en asumirlos.

Dentro de ese elenco de reconocidos docentes e investigadores se sumó el entusiasta Juan Carlos Garavaglia. Precedido por el reconocimiento de sus investigaciones fue, para los jóvenes graduados y los alumnos de la carrera, un encuentro con el Maestro que exponía su entusiasmo y su pasión por enseñar que la docencia no solo implicaba transmitir un saber sino también, construir conocimiento. Como experiencia personal tengo presente aquellas clases a las que pude asistir cuando dictó un concurrido seminario en el Aula Magna de la Universidad. Los concursantes quedamos fascinados con aquella demostración de conocimiento, histrionismo y de cultura general de la que hizo gala. Estaba feliz y nosotros maravillados $\mathrm{y}$, al mismo tiempo, conscientes de todo lo que debíamos aprender, incluso, para poder comprender la complejidad de ese escenario social del mundo colonial que nos presentaba. Todo tan alejado de aquello en lo que nos habíamos (des)formado. Con su infinita generosidad se propuso que pudiéramos comprender el peso que tuvieron los mercados interiores en la organización social del espacio colonial. Nos aproximó a historiadores para nosotros absolutamente desconocidos como Carlos Sempat Assadourian para-nuevamente- acercarnos a la compleja lectura de Halperín Donghi. Fue tal la contundencia de aquellas clases modelos que, para muchos como en mi caso- vivimos una experiencia ambigua que iba de la fascinación por el descubrimiento de una Historia que mostraba claramente que no era "el cementerio de las elites" -como una profesora nos supo decir sin pudor en aquella formación universitaria de los tiempos de la dictadura- a la percepción de que sería casi imposible conseguir emularlo. El tiempo mostraría que obviamente la meta no era llegar a ser como el "Gara" sino, abrazar -desde nuestro propio lugar, con nuestros límites y posibilidades- con entusiasmo y compromiso profesional la formación permanente en la docencia y la investigación.

La expectativa por su llegada a nuestra carrera fue totalmente superada por la dinámica de su trabajo. Apoyado por ese conjunto de colegas que participaron de su iniciativa fue posible concretar la creación del Instituto de Estudios Histórico Sociales (IEHS). Un modelo de centro de investigación no solo para nuestra casa de estudios, sino la posibilidad de que otras carreras en 
distintos punto del país pudieran seguir estos derroteros. Era posible hacer una historia profesional desde el interior e, incluso, desde una Universidad pequeña. En el acta de su creación del 2 de octubre de 1986, aparecen las firmas de Eduardo Míguez, Juan Carlos Grosso, Carlos Astarita, Raúl Mandrini, Susana Bianchi, Zacarías Moutoukias, Daniel Santamaría, María Dolores Béjar, Graciela Malgesini, Antonio Manna. Junto a ellos, los miembros asistentes graduados de la UNICEN- María E. Argeri, María E. Bilbao, Marta Brugi, Daniel Dicósimo, Gabriel Huarte, Miriam Iglesias, Nancy Pastor, Hernán Otero, Andrea Reguera, Analía Soria, María E. Spinelli, Fernando Urquiza, Guillermo Velázquez, Blanca Zeberio.

Nuevos horizontes se abrieron en la docencia y la investigación. Allí estaban ellos para mostrar que en el IEHS se construía esa renovación historiográfica desde el compromiso que implicaba la investigación como una pareja ineludible de la docencia. Fue así que, en ese compromiso colectivo, se construyó esa idea de que investigar implicaba reconocer las pautas y los procesos de acción mediante los cuales se renovaba un relato lineal de la Historia dando lugar a otros protagonistas, a otros métodos, a nuevos problemas e hipótesis de trabajo y a un diálogo estrecho con otras disciplinas de las Ciencias Sociales. Si la Historia era un campo en permanente construcción, entonces, esos alumnos y jóvenes graduados podían emprender el camino duro, competitivo pero ciertamente estimulante de la profesionalización. El Departamento de Historia y el IEHS fueron los impulsores de esa formación de recursos humanos que tendrían la valiosa experiencia de continuar sus estudios de postgrado en centros académicos de excelencia a nivel internacional y nacional.

Eran tiempos de cambios donde se abrazaban convicciones ideológicas y compromisos de fe con la democracia. Todo estaba por hacerse en un contexto político, social y cultural que daba las condiciones de posibilidades para que las universidades y sus actores se encontraran, luego de arduas disputas, participando en la construcción de un horizonte acerca del lugar que tendría la construcción del conocimiento y la formación de los recursos humanos para una sociedad que iniciaba el camino de su reconstrucción luego de la larga y oscura noche de la última dictadura en la Argentina. Esa innovación mostraba de modo palmario que, el cambio profesional no solo involucraba la trayectoria individual sino que debía ser acompañado por un contexto donde se desarrollara la tarea profesional. Así, se asumió que lo colectivo y lo individual constituía una pareja indisociable y necesaria para promover y afianzar la ansiada transformación.

Incansable en la generación de proyectos, la tarea de Juan Carlos continuó. El instituto tenía que tener su propia revista, fue así que hizo su aparición el Anuario IEHS. Fueron de gran impacto esos primeros números. Uno de los temas que sirvió de puntapié en aquellas páginas fue mostrar en su complejidad el territorio de la campaña de Buenos Aires y sus pobladores durante el periodo colonial y el siglo XIX. Fueron claves las publicaciones de los estudios de Carlos Mayo, Jorge Gelman, Raúl Fradkin, Eduardo Míguez y el propio Juan Carlos Garavaglia que dieron cuenta de una llanura pampeana que no era un espacio habitado solo por algunos gauchos de a caballo y grandes terratenientes. Aún hoy se recuerda su artículo donde interrogaba de manera provocadora si "¿Existieron los gauchos?". ${ }^{1}$ Aquel legendario debate que entablara con Carlos Mayo, Samuel Amaral y Jorge Gelman, sigue siendo

${ }^{1}$ GARAVAGLIA, Juan Carlos “¿Existieron los gauchos?”, Anuario IEHS, núm. 2, 1987, pp. 42-52. 
atrapante no solo por su aporte historiográfico sino porque revela la pasión puesta en la investigación y en una buena pluma que reflejara ese profuso y exquisito trabajo de archivos de cada uno de ellos. Trabajos pioneros que desafiaron aquella representación que hundía sus raíces en dos grandes obras literarias, Facundo y Martín Fierro. Nuevas preguntas, con otros enfoques metodológicos, hechas a fuentes documentales como padrones, registros parroquiales y fuentes judiciales, permitieron reconstruir la complejidad de aquella sociedad.

A la par que continuaba con su prolífica tarea de investigación y producción, durante cinco años tuvimos el enorme privilegio de tenerlo en Tandil como profesor de Historia Colonial, como Director del IEHS y del Anuario. Cuando volvió en 1991 hacia Francia, donde fue designado Directeur d'Études en la misma EHESS que lo había consagrado doctor, dejó una huella imborrable y un gran vacío. Contamos con su presencia en diversas oportunidades, sin embargo, sus visitas fueron más esporádicas y estuvieron marcadas por la nostalgia y el dolor de una ausencia, la de su hermano de la vida Juan Carlos Grosso. Todos sabíamos lo que le costaba cada regreso, sin embargo, hace tan solo dos años atrás no declinó ante una nueva invitación.

Su última visita fue en octubre de 2015, junto a la entrañable Elisa. Con su habitual entusiasmo, increíble afecto y generosidad nos regaló la posibilidad de volver a escucharlo en sus nuevos rumbos de investigación. El IEHS -su casaestaba de fiesta, volvía a recibirlo y allí estaban los colegas de la Carrera, docentes de escuelas medias expectantes por con su admirado profesor, y los alumnos que estaban ansiosos por conocer a quien leían y que lo admiraban aún más después de leer sus memorias. Ante la cantidad de público que lo fue a escuchar, su gran preocupación era no cumplir con las expectativas de los estudiantes que lo conocían como uno de esos autores claves que se citan en los programas de las materias que curan. Su charla, titulada "Desigualdad, finanzas y guerra. Argentina, 1865-1870", dio cuenta de qué modo -a pesar de la escasez de las fuentes que disponía- su sensibilidad historiográfica lo llevó a interesarse por mostrar otra de las formas de la desigualdad en aquel contexto como fue, el reparto de los recursos de la Nación entre Buenos Aires y las provincias cuatro años después de Pavón. Todos lo escuchamos atentamente reflexionando sobre esa pasión por bucear en nuevos archivos detrás de ese indicio a decir de Ginzburg que permitiera tejer los hilos de la Historia. Una vez más, consiguió transmitir su conocimiento al tiempo que mostró los entretelones de un oficio signado por la incasable y atrapante búsqueda de archivos. Y su desafío era precisamente ese, poder avanzar más allá de la parquedad de las fuentes. En estos últimos tiempos había asumido ese desafío ante el riesgo de encontrar pocas evidencias, a propósito, cabe recordar su iniciativa de estudiar la Guerra del Paraguay con el objetivo de investigar sobre la formación del Ejército argentino, en la línea de estudios que venía realizando acerca de la construcción del Estado en Latinoamérica. ${ }^{2}$

\footnotetext{
${ }^{2}$ No puedo dejar de referenciar sus lúcidos comentarios respecto a la Guerra del Paraguay a la que consideró como “...el último rescoldo que quedaba del conflicto entre Portugal y España, y en relación a las pretensiones imperiales del Brasil sobre el Río de la Plata". De modo sugerente su propósito era el de estudiar el problema de las fuerzas de guerra en el Río de la Plata a los efectos de analizar el proceso de construcción estatal y de un ejército nacional. Con su habitual modo de problematizar y su sensibilidad para abordar los temas de investigación, entendía que de ser accesibles los documentos sobre esos acontecimientos podrían escribirse, al menos, seis o siete tesis que indagaran sobre el problema del cólera y las condiciones higiénicas, las ventas forzosas a los soldados, la cuestión de la financiación en el lugar -porque entendía que el problema macro de financiación está más o menos claro- las relaciones entre los soldados, entre
} 
Como sea, aquella presencia terminó con una insoslayable pregunta por su militancia en los años setenta y por la publicación de su último libro Una juventud en los años sesenta. Como supo expresar lúcidamente, en el libro se animó hacer confesiones acerca de cosas que no lo hacían sentir orgulloso, pero que sentía que debía hacerlas, sino -como se interpelaba y nos interpeló- ¿para qué escribe uno sus memorias? Si ese ejercicio nació primero como una experiencia personal, inmediatamente se transformó-tal como lo expresó- en algo dedicado a los jóvenes, quienes tienen la misma idea borrosa sobre esa época que él tuvo sobre la crisis de los años treinta. Lo que se propuso era ver si, a través de esta experiencia personal, podía aportar algo. Como manifestó en otra oportunidad "Me costó muchísimo, fueron dos años de sufrimientos muy intensos, porque es evidente que uno recuerda caras, personas. Cuando esas personas han desaparecido o las mataron, entonces los recuerdos son duros, y escribir sobre eso por momentos me costó lágrimas. Pero estoy contento de haber hecho el esfuerzo, porque era una deuda que tenía conmigo y son esas deudas que uno tiene que tratar de saldar, sino te quedas atragantado".

Tal como advertirán los lectores y las lectoras, ese paso de Juan Carlos por el IEHS fue conmovedor, no hizo más que reafirmar nuestra admiración, respeto pero, sobre todo, nuestro profundo cariño. Su partida fue sin despedidas, no podía hacerlo, estaba muy sensible, era un hasta siempre, nos juntamos nuevamente en cualquier momento. Así entendimos nosotros, y esa oportunidad para volver a juntarnos vendría de la mano de la celebración de los 30 Años del IEHS. Al organizar esa actividad académica en el 2016, por supuesto el Gara era infaltable. La invitación por mail tuvo su inmediata y entusiasta respuesta. Todo estaba preparado para recibir a los queridos y admirados colegas y, muy especialmente, para que Juan Carlos fuera el anfitrión, porque el IEHS fue su creación, era su casa. Pocos días antes de concretarse las jornadas su mensaje nos decía que no podría estar presente. Sus cálidas palabras traslucían la preocupación por la salud de un ser querido y por algunos malestares que lo aquejaban. Fue un afectuoso intercambio, donde me permitió expresarle que comprendía perfectamente sus sentimientos porque también estaba atravesando por un tiempo de mucho dolor y lucha con la salud de mi madre. Su último correo fue una caricia al corazón, de esas que te reconfortan ante tanta desesperación. En medio de sus propios temores, de sus pesares tuvo la generosidad de siempre, aquella que lo caracterizó a lo largo de su vida. Tuvo la enorme disposición de pensar en el otro, de dar un mensaje de aliento, de estar, de acompañar. Luego, el silencio de unos días, la preocupación porque no hubo respuesta a un breve mensaje donde le preguntaba cómo estaba su salud. Una preocupación que anunciaba la más triste noticia. Regularmente vuelvo a leer su último mensaje porque, como el día que lo recibí, sigue siendo ese gesto de afecto reparador tan necesario cuando nos invade el desánimo.

\section{Itinerarios de una investigación y la guía del Maestro}

Tras la tristeza de aquella noticia vino el inevitable recuerdo de lo que Juan Carlos dejó en lo personal y -obviamente- a nivel profesional. Volver a leer sus

los oficiales. Por eso su aspiración era la de poder leer esos documentos a los que aún no había logrado acceder. RABINOVICH, Alejandro - ZUBIZARRETA, Ignacio "Entrevista a Juan Carlos Garavaglia", Quinto Sol, Vol. 19, núm. 3, septiembre-diciembre 2015, pp. 1-8:

http: / / dx.doi.org/10.19137/ quintosol-2015-190307 
trabajos resulta no solo un viaje por ese mundo social que supo reconstruir con fineza sino una fuente de inspiración y de guía. Gracias a ese minucioso y exhaustivo trabajo de archivos, con el que mostró las tramas de sus relaciones sociales del mundo de la campaña bonaerense, me permitió hacer un giro en mi propio derrotero por la investigación. Era precisamente ese escenario, analizado con su exquisita sensibilidad, el que comencé a transitar. En efecto, hace unos años, debido a nuevos intereses, realicé un giro en mi trabajo sobre la historia social de la educación de fines del siglo XIX y los albores del XX, poniendo el foco de interés en dos líneas de estudio: por un lado, la escolarización en la campaña bonaerense a lo largo del siglo XIX, lo que inevitablemente me llevó en estos últimos dos años a plantear otra cuestión como es, la presencia de la niñez en la ciudad y su campaña desde la segunda mitad del siglo XVIII y a lo largo del siglo XIX. ${ }^{3}$

En el caso de la radicación de las escuelas elementales en la campaña bonaerense surgieron una serie de interrogantes a partir de los indicios que las propias fuentes aportan, pero -sin dudas- el mayor aporte vino a partir de las orientaciones que la lectura de los trabajos de Juan Carlos Garavaglia, Raúl Fradkin, Jorge Gelman, entre otros, promueven al develar los rasgos de esa sociedad de frontera. ${ }^{4}$ Como sabemos la historiografía tradicional, que forjó el mito de la formación de la nación sobre la base de la civilización marcada por el ritmo de la ciudad de Buenos Aires, dejó impresa aquella imagen de un espacio signado por la barbarie. Como lo expresara Juan Carlos Garavaglia,

"el desierto es una de las imágenes más difundidas para nuestro siglo XIX rural; un desierto de gente y por lo tanto, un desierto de técnicas, de saberes, de tradiciones culturales, de formas de sociabilidad, de relaciones sociales... Aquello era algo así como la nada sociológica, el vacío social, no existía 'todavía' una sociedad." 5

La recuperación de la democracia en Argentina durante los años ochenta del siglo XX, hizo posible revisar la interacción entre hombre-naturaleza y complejizar desde perspectivas socio-demográficas y económicas ese paisaje. Así, fue posible mostrar una dinámica social y económica que desveló un mundo mucho más amplio que esa extensa geografía solo poblada por estancieros, gauchos y malones indígenas. Aparecieron actores claves, como los terratenientes, chacareros arrendatarios, gauchos que contribuyeron a la exitosa inserción de la región al mercado mundial. A su vez, la expansión agraria

\footnotetext{
${ }^{4}$ Un diálogo permanente y obligado respecto a esta cuestión, surge a partir de los valiosos trabajos de José Bustamante Vismara. Entre muchos otros, podemos citar: BUSTAMANTE VISMARA, José Las escuelas de primeras letras en la campaña de Buenos Aires (1800-1860), Ediciones Asociación Amigos del Archivo Histórico, La Plata, 2007; "Construcción estatal y desarrollo escolar (Córdoba, Buenos Aires y Entre Ríos, 1820-1850)”, en Historia de la educación. Anuario, Buenos Aires, 2016, vol. 17, pp. 50-71; "De cómo las escuelas de primeras letras se transformaron en escuelas primarias en la campaña de Buenos Aires a mediados del siglo XIX", Entrepasados, Buenos Aires, 2008, vol. XVII, p. 127-142; "Una historia regional comparada de la educación elemental. (Córdoba, Buenos Aires y Entre Ríos, 1810-1852)” en: MARTíNEZ BOOM, Alberto y BUSTAMANTE VISMARA, José Escuela pública y maestro en América Latina. Historias de un acontecimiento, siglos XVIII-XIX, Buenos Aires, 2014, pp. 211-235. Un trabajo pionero fue el de: NEWLAND Carlos "La educación elemental en Hispanoamérica: desde la independencia hasta la centralización de los sistemas educativos nacionales", The Hispanic American Historical Review, núm. 71, 2, 1992, pp. 335-364.

${ }^{5}$ GARAVAGLIA, Juan Carlos Poder, conflicto y relaciones sociales. El Río de la Plata, XVIII-XIX, Homo Sapiens, Rosario, 1999, p. 15. Resaltado del autor.
} 
promovió la incorporación de tierras y el avance sobre una frontera de contactos intra e interétnicos e incluso intersociales. ${ }^{6}$

En aquel mundo social en el que parecieron confrontar la civilización con el salvajismo, el territorio poblado con el desierto, esta historiografía renovadora dio cuenta de un carácter móvil y abierto que lo convirtió en un lugar de oportunidades económicas y de ascenso social que, en la mayor parte de los casos, no estaban destinados a perdurar. Tal como se demostraron, esa frontera estuvo marcada por una larga historia de la llamada "conquista del desierto" por el reparto de la tierra pública, por la expansión horizontal de las actividades económicas en nuevas tierras -la ganadería primero (ovina y vacuna, en ese orden), la agricultura después-y por el progresivo asentamiento de inmigrantes en esas tierras -nacionales primero, extranjeros posteriormente. ${ }^{7}$

Los pueblos de la campaña bonaerense -no más de una treintena pequeñas comunidades- en las primeras décadas del siglo XIX contaban con una población que oscilaba entre 500 y 3000 habitantes. Para 1850, algunos de ellos, habían aumentado a 7000 u 8000 pobladores. Por entonces, un $40 \%$ del total de los habitantes de la región serían menores de 14 años. Las altas tasas de mortandad infantil harían suponer que, en un pueblo de 1000 habitantes, apenas unos 100 estarían entre los 6 y los 12 años. Fueron recurrentes las migraciones de hombres adultos provenientes de la región interior del país, atraídos por la demanda estacional de mano de obra que se producía con la cosecha estival. Cuando fueron acompañados por sus familias se transformaron en pobladores permanentes. Para inicios de esa década del veinte, la población de la campaña promediaba alrededor de unas 57.000 personas y aglutinaba aproximadamente a 7,8\% del total poblacional del territorio argentino. Al promediar el siglo alcanzó unas 100.000 personas. El Primer Censo Nacional de Población -en 1869- reveló que más de 330.000 individuos habitaban la campaña de Buenos Aires, con lo cual casi se duplicaba a los habitantes de la ciudad. Esa aceleración del crecimiento demográfico se vinculaba al aporte de la migración que recibió el territorio que superó ampliamente el aporte del crecimiento natural en la campaña. ${ }^{8}$ La presencia de la inmigración -desde las provincias y desde el aporte europeo con las migraciones "tempranas" marcó una estructura demográfica "joven" y con predominio masculino, una cuestión que será relevante para nuestra línea de investigación.

En ese espacio poblado por familias campesinas de labradores y pastores, la reproducción biológica, social y económica de la fuerza de trabajo se realizaba a través del desempeño combinado de actividades diversas en un solo ámbito, por lo cual no resulta admisible la oposición entre una esfera doméstica y una esfera económica, concebidas como departamentos estancos. La conjunción en una sola entidad como productoras y grupos familiares les confería a estas unidades características, necesidades y posibilidades

\footnotetext{
${ }^{6} \mathrm{Al}$ respecto ver, entre otros aportes sobre el tema: MANDRINI, Raúl "Indios y fronteras en el área pampeana (Siglos XVI y XIX). Balance y perspectivas", Anuario IEHS, núm. 7, 1992, pp. 5972; MAYO, Carlos Vivir en la frontera. La casa, la dieta, la pulpería, la escuela (1770-1870), Biblos, Buenos Aires, 2002; ORTELLI, Sara y RATTO, Silvia "Introducción dossier: Poder, conflicto y redes sociales en la frontera pampeana, siglos XVIII-XIX", Trabajos y Comunicaciones, núm. 32/33, 2006, pp. 77-85.

7 PALACIO, Juan Manuel La paz del trigo. Cultura legal y sociedad local en el desarrollo agropecuario pampeano, 1890-1945, Edhasa, Buenos Aires, 2004, p.42.

${ }^{8}$ Al respecto ver el análisis de: MASSE, Gladys "El tamaño y el crecimiento de la población desde la Conquista hasta 1870", en OTERO, Hernán (dir.) Población, ambiente y territorio, Tomo 1, Editorial Universitaria EDHASA, Buenos Aires, 2012, pp. 143-172.
} 
particulares. A ellas les tocaba la responsabilidad de organizar en su totalidad el ciclo de la reproducción de sus miembros. ${ }^{9}$

Como ya ha sido ampliamente explicado hubo diferentes valoraciones en las formas de ocupar, habitar, transitar y vivenciar este espacio, tanto entre los habitantes residentes, los agentes estatales y los foráneos. Así se advierten experiencias discrepantes respecto de la vida social, económica y cultural de la campaña. Al respecto, los relatos de los viajeros aparecen como testimonios reveladores de la percepción que tenían algunos contemporáneos de aquella realidad social. Su visión europeizante mostraba la sorpresa de encontrarse con la otredad y reforzaba aquella imagen de un territorio sumido en la barbarie y la rusticidad. ${ }^{10}$

Nuevamente fue Juan Carlos Garavaglia quien nos permitió viajar en el tiempo para introducirnos en las viviendas de los chacareros y labradores, esos pequeños y medianos productores que tan bien conocía, para explicar que sus moradas eran bastantes simples, hechas de adobe y paja. Estaban conformadas por la cocina, la sala-comedor, una o dos piezas adyacentes y la ramada. Allí se comía, se compartía el mate, se dormía, se charlaba y se anudaban todo tipo de relaciones, incluyendo a todos los miembros del grupo familiar. Los hacendados, por su parte, tenían casas más confortables. Grandes cocinas donde convivían peones y esclavos; techos de teja y paredes de ladrillos cocidos o de adobe; alguna reja de madera -excepcionalmente de hierro- adornaba dos o tres ventanas sin vidrios. ${ }^{11}$ La mayoría de las familias de la campaña eran nucleares compuestas por los padres y los hijos, incluyéndose a los "entenados", o sea, los hijos habidos en una pareja anterior de uno de los padres. A veces, algún "agregado" o huérfano que tenían una relación lejana con la familia vivía también en la casa. El tipo de viviendas eran diferentes, según las posiciones socioeconómicas que ocupaban sus habitantes.

Aquella fue una sociedad caracterizada por la costumbre de regirse por normas implícitas consensuadas entre las diferentes partes. Esta trama social preexistente chocó contra el marco normativo legal que las nuevas autoridades - pertenecientes a la elite urbana ilustrada, por lo general- intentaban construir. Así, la campaña bonaerense fue testigo de una constante tensión entre la ley y las prácticas sociales que allí regían. ${ }^{12}$

Por otra parte, la construcción del orden republicano en el Río de la Plata, transitó entre la redefinición de la condición de vecindad y la construcción de la ciudadanía. La vecindad y la ciudadanía implicaron conceptos diferentes. La primera, remitía al domicilio y la segunda, al estatuto político. La condición de vecino se relacionaba con la prestación de servicios, pago de impuestos y acceso a los bienes de la comunidad lo que exigía una relación constante y directa con la autoridad. La vecindad en el mundo indiano estaba ligada a la descendencia

\footnotetext{
${ }^{9}$ Sobre las características de las familias campesinas es sugerente el trabajo de: de APPENDINI, Kirsten El campesinado en México. Dos perspectivas de análisis, El Colegio de México, México, 1983. ${ }^{10}$ Entre otros ver: Mac CANN, William Viaje a caballo por las provincias argentinas, Taurus, Buenos Aires, 2001 [1847].

${ }^{11}$ GARAVAGLIA, Juan Carlos "Ámbitos, vínculos y cuerpos. La campaña bonaerense de vieja colonización", en DEVOTO, Fernando y MADERO, Marta (dirs.) Historia de la vida privada en la Argentina, Tomo I, Taurus, Buenos Aires, 1999.

12 Al respecto ver: FRADKIN, Raúl "Cultura jurídica y cultura política: la población rural de Buenos Aires en una época de transición (1780-1830)" en FRADKIN, Raúl La ley es tela de araña. Ley, Justicia y Sociedad Rural en Buenos Aires, 1780-1830, Prometeo, Buenos Aires, 2009, pp. 159186; FRADKIN, Raul “Entre la ley y la práctica: la costumbre en la campaña bonaerense de la primera mitad del siglo XIX", Anuario IEHS, núm. 12, 1997, pp.141-156.
} 
legítima por vía paterna sin exclusión de otras pertenencias referidas al derecho de sangre. Por su parte, la ciudadanía se encontraba sostenida básicamente por la vecindad pero con la Revolución de mayo se dejaron atrás los privilegios que daba el pertenecer al Cabildo por ser vecino. La propia dinámica revolucionaria, y la necesidad de legitimar el nuevo orden, promovió la ampliación de la sociedad política que, acompañada del reconocimiento de la vecindad, se convirtió en el modo cultural y jurídico adecuado para identificar a los incluidos socialmente, exigirles el cumplimiento de la ley y las obligaciones. Aquella búsqueda de la construcción de una nueva legitimidad política hizo posible que transitara de la condición de súbdito a ciudadano. ${ }^{13}$

Fue a partir de los rasgos particulares de ese mundo de la campaña bonaerense los que guiaron para que Juan Carlos Garavaglia pudiera demostrar de qué modo, la consolidación del Estado no fue el resultado de un proceso lineal sino el producto de una dinámica compleja y contradictoria. Con absoluta claridad advertía que, la vasta producción sobre la historia de Iberoamérica durante la primera mitad del siglo XIX, el "Estado" aparecía como un personaje central, sin embargo, muy pocos habían hecho el esfuerzo por definir y analizar en qué consiste el Estado. ${ }^{14}$ En efecto, teóricos como Max Weber, Antonio Gramsci y Pierre Bourdieu, entre otros, fueron los referentes a los que apeló para explicar que el poder estatal fue la resultante de un "entramado de relaciones sociales de dominación", permitiendo la institucionalización de un poder separado de la sociedad. En esa dinámica relacional, las instituciones burocráticas fueron los instrumentos que hicieron factible que se cumplieran con sus devenires- las funciones estatales. Esto lleva a presuponer al Estado como el producto social de una interacción dinámica promovida por el proceso de transformación económica y social, donde se implementaron estrategias de dominación y de búsqueda de consenso. Sin que implique una contradicción, se pueden reconocer las estrategias que se ensayaron en pos de garantizar la legitimidad y la hegemonía del nuevo orden estatal así como las acciones tendientes a la coerción, las que también debieron desplegarse con cierto grado de consenso por parte de las comunidades. ${ }^{15}$

\section{El largo camino por la configuración de un modelo de instrucción pública}

\footnotetext{
13 CANSANELLO, Carlos De súbditos a ciudadanos. Ensayo sobre las libertades en los orígenes republicanos. Buenos Aires, 1810-1852, Imago Mundi, Buenos Aires, 2003.

${ }^{14}$ GARAVAGLIA, Juan Carlos Construir el estado, inventar la nación. El Río de la Plata, siglos XVIIIXIX, Prometeo, Buenos Aires, 2007, p. 227.

${ }^{15}$ Dentro de las diversas corrientes que se han dedicado a revisar los procesos de formación del Estado nacional en Latinoamérica, distintos autores han ido mostrando la cara más cotidiana, labrada, negociada y gris de estos fenómenos, señalando las imbricadas y personalizadas relaciones entre el Estado y sus aparatos legales, militares e ideológicos y los sectores subalternos. Al respecto ver: BOHOSLAVSKY, Ernesto y ORELLANA, Milton Godoy (eds.) Construcción estatal, orden oligárquico y respuestas sociales: Argentina y Chile, 1840-1930, PrometeoUNGS, Buenos Aires, 2010. Un trabajo de cita ineludible al respecto, que estudia los procesos de formación de los Estados mexicano y peruano, desde la perspectiva del State-building en el cono sur del continente americano en tanto muestra la fragilidad del orden estatal, de su carácter de compromiso de fuerzas y la ausencia de un proyecto autoconsciente y que da cuenta de la participación de los sectores subalternos en la política de las primeras décadas republicanas es el de: MALLON, Florence Peasant and Nation. The making of Postcolonial México and Perú, University of California Press, Berkeley, 1994. En los últimos tiempos se puede dar cuenta, gracias a una interesante producción, de dos dominios correspondientes a la política: la política de la "elite" y la política de los "subalternos". En tal sentido, ha sido una guía el trabajo de: GUHA, Ranahit Las voces de la historia y otros estudios subalternos, Crítica, Barcelona, 2002.
} 
A partir de esas lúcidas explicaciones, surge el interés por estudiar de qué modo hacer Escuela era una forma también de hacer Estado focalizando la atención en la campaña bonaerense a lo largo del siglo XIX. ${ }^{16}$ Un recorrido temporal que implica reconocer las continuidades entre los tiempos de la Colonia y el proceso de conformación de la nueva legitimidad republicana, tras el resquebrajamiento del antiguo orden y que, en materia de instrucción pública, culminó en la provincia de Buenos Aires con la sanción de la Ley de Educación Común y Obligatoria de 1875. Esta ley fue un antecedente -más allá de que garantizaba la enseñanza de la religión católica en las escuelas- de la Ley 1420 promulgada por el gobierno nacional para la Capital Federal y los llamados Territorios Nacionales en 1884, mediante la cual se garantizó en la Argentina la educación pública, gratuita, gradual, obligatoria destinada a extender la alfabetización a todos los niños y niñas de la república.

Estas leyes contaron con antecedentes poco estudiados tales como, las iniciativas que propiciaron las autoridades y los vecinos antes de que se configurara el Estado provincial y nacional.

Para avanzar en ese sentido, resultó imprescindible reconocer las características sociales, económicas y políticas de la campaña bonaerense. Solo así fue posible comprender el sentido de las primeras iniciativas en favor de la radicación de escuelas elementales por parte de las autoridades civiles. Iniciativas -muchas veces acompañadas por las propias comunidades- que mostraron sus límites ante la debilidad política y las mediaciones que le impuso aquella realidad social. Esto implicó que se generaran diversos conflictos de distinto tenor y que se hacían evidentes cada vez que las autoridades provinciales ensayaban iniciativas, muchas veces improvisadas pero que ciertamente revelaban esos primeros intentos por instituir y dar forma a la instrucción pública. Una aproximación que, permite en tal sentido, reflexionar a partir de la presencia de esas escuelas y en el marco de aquel paisaje social con sus comunidades fuertes y un lábil orden político- sobre ese complejo proceso de conformación del orden republicano y la estatalidad moderna.

Las dificultades que se plantearon para realizar este trabajo fueron de tipo heurística-metodológicas. La escasez de fuentes oficiales que permitan recuperar las políticas educativas, la dispersión, diversidad y vacíos en el registro documental, sumado al mal estado de los reservorios documentales, son los obstáculos a superar. Sin embargo, a pesar de esos oscuros, hay indicios que permiten mostrar de qué modo, en una cartografía social eminentemente rural, hubo interés por promover la alfabetización y el acceso a una cultura letrada, condición estimada necesaria para extender los beneficios de la civilización y para promover el pasaje de la condición de súbditos de la corona a la de ciudadano de la República. ${ }^{17}$

Muy escuetamente podemos afirmar que, más allá de la lábil presencia de la estatalidad y en el marco de su proceso de construcción, las primeras escuelas elementales -surgidas en el contexto colonial- se continuaron promoviendo con la meta clara de configurar el nuevo orden político. En la prensa de la

\footnotetext{
${ }^{16}$ Un trabajo que también resulta iluminador, más allá de que centra su análisis en otro espacio y en otro proceso temporal es el de: ROCKWELL, Elsie Hacer escuela hacer estado. La educación posrevolucionaria vista desde México, El Colegio de Michoacán, CIESAS, CINVESTAV, México, 2007.

${ }_{17}$ Un valioso y erudito trabajo que ha sido inspirador por su enfoque regional es el de: ARREDONDO, Adelina En la senda de la Modernidad. Un siglo de Educación en Chihuahua, 17671867, 2 Tomos, El Colegio de Michoacán, Michoacán, 2011.
} 
época, comprometida con el ideario revolucionario, se reconocía que era prioritario difundir las luces de la instrucción con el objeto de formar a un ciudadano "virtuoso e ilustrado" sobre el que se cimentara la vida republicana. Con vehemencia se afirmaba que los pueblos embrutecidos y contagiados por la opresión y el error, no serían susceptibles de ninguna reforma pacifica mientras no "se enseñase gratuitamente a todos los niños y jóvenes pobres lo que es útil y necesario a la sociedad..."18

De la tarea participaron improvisados preceptores que se pusieron frente, con una muy pobre infraestructura, a un grupo generalmente numeroso de niños y niñas que acudían a la escuela irregularmente. Una educación elemental donde la enseñanza religiosa ocupaba un lugar preeminente basada en el catecismo de Astete (o en su lugar de Ripalda) para continuar luego con el de Fleury. Ambos textos usados en la etapa colonial. Se podría decir de un modo más o menos sintético que, más allá de ciertos intentos por incorporar algunas novedades pedagógicas como el sistema lancasteriano, en estas escuelas los y las escolares leían, por disposición de los cabildantes, el "Tratado sobre ensayos del Hombre" de Juan Esqueicoz - que ya había aconsejado a difundir en España el ilustrado Jovellanos- y eran evaluados en exámenes públicos -también ya implantados en España en su momento. Tal vez, lo más novedoso estuvo en esa voluntad de promover la orientación patriótica de la educación en 1812 que reglamentó el uso de la escarapela y la conmemoración de las fechas patrias. ${ }^{19}$ Una segunda novedad, estuvo dada por la disposición que promovía la supresión del castigo corporal a los niños proclamada por la Asamblea Nacional de 1813. Sin lugar a dudas, aquella iniciativa respondía a un clima de época donde se procuraba erradicar la ofensa al cuerpo de los futuros hombres útiles de la patria que, por otra parte, no estaba acorde con esa nueva economía moral que propendía a la moderación en el uso de la fuerza física. ${ }^{20}$

El año 1820, con la caída del gobierno central de las Provincias Unidas del Río de la Plata, en la ciudad de Buenos Aires y la campaña bonaerense se asistió a esa "feliz experiencia" caracterizada por una serie de reformas políticas, económicas, sociales y culturales. El objetivo fue el de consolidar un nuevo orden institucional y social al tiempo que se intentó realizar, de manera pedagógica, una transformación modernizadora que fuera capaz de reformar la sociedad. El gobernante Partido del Orden, encontró en la figura de su ministro liberal Bernardino Rivadavia el máximo exponente de un proyecto que buscó revertir la situación de una sociedad, percibida como carente de pautas de

\footnotetext{
${ }^{18}$ El Censor, núm. 80, 27 de marzo de 1817, p. 2. Sala del Tesoro (ST), Biblioteca Nacional (BN), Buenos Aires.

${ }^{19}$ Estas iniciativas han sido analizadas por los citados trabajos de José Bustamente Vismara y en una serie de artículos y capítulos de libros donde se exponen del tipo de dificultades que se debieron sortear pero también los medianos logros que se consiguieron. Se ha profundiza aún más esta cuestión en: LIONETTI, Lucía "Sujetos sociales, escuelas y comunidades rurales. Disputas de poder en el escenario de la campaña bonaerense (1810-1875)", en Historia y Memoria de la Educación, UNED, Madrid (en prensa)

Cabe destacarse que ya nos había advertido Juan Carlos Garavaglia de qué modo había operado en pequeños episodios la construcción del imaginario de la nación identitaria y, específicamente, cómo a través de las Fiestas Mayas se recuperaron viejas tradiciones ibéricas y locales para encabalgarlas en un proceso de invención de la identidad. Ver. "A la nación por la fiesta: Las Fiestas Mayas en el origen de la nación el Plata", en GARAVAGLIA, Juan Carlos Construir el estado, inventar la nación..., cit., pp.57-88.

${ }^{20}$ La cuestión del castigo físico en las escuelas elementales ha sido analizada en: LIONETTI, Lucía "Cuerpo y castigo. La penalidad física en las escuelas elementales de Buenos Aires y la campaña en el siglo XIX", Quinto Sol, Vol. 19, núm. 2, 2015, pp. 1-21.
} 
sociabilidad y civilidad, de una cultura ilustrada, de una opinión pública y de un cuerpo de ciudadanos.

Ese paradigma ilustrado fue el que inspiró medidas como la creación de la Universidad de Buenos Aires en 1821, incorporando bajo su administración las escuelas primarias de la ciudad y la campaña con el propósito de dar forma a un sistema general de educación en el que se adoptara el método lancasteriano. Durante esos años se convocó a la Sociedad de Beneficencia para administrar la instrucción de las niñas. ${ }^{21}$ Más allá de lo fragmentario de las medidas y de la discontinuidad, existió un propósito de mejorar la calidad de la oferta educativa no solo fomentando la creación de escuelas sino procurando reglamentar la tarea de los preceptores. ${ }^{22}$ Hacia 1828 el gobierno escolar se separó de la Universidad a raíz de un conflicto interno en torno al sistema lancasteriano que originó la oposición contra el Director Baladía y el Rector de la Universidad Valentín Gómez.

Para el caso de la campaña, se decidió específicamente cambiar las Juntas Protectoras por las Juntas Inspectoras conformadas por el Juez de Paz y dos "vecinos respetables" del lugar. Quienes quedaban fuera de esa función eran los curas párrocos en una evidente señal de la impronta liberal del momento. Sin embargo, los testimonios dan cuenta de que las autoridades y vecinos locales continuaron acudiendo a los religiosos por su llegada a la comunidad.

Más allá de esos ingentes esfuerzos, y pasado el breve intento de centralización que llevó a la presidencia al liberal Bernardino Rivadavia, las nuevas autoridades de Buenos Aires en su balance sobre el estado de la escolarización reconocieron los mayores logros en la educación de las niñas y, con ello, en la acción de la Sociedad de Beneficencia. Diez años después, durante el régimen del caudillo federal Juan Manuel de Rosas, se decretó el cierre virtual de las escuelas y el desmembramiento de la Universidad de Buenos Aires, declarando que el gobierno no podía abonar los sueldos. El régimen rosista en sus dos mandatos (1829-1832 y 1835-1852) dejó su sello y una discontinuidad en materia de educación. La enseñanza particular que se había mantenido a lo largo de estos años con regularidad y sin mayores exigencias y controles por parte de las autoridades públicas de turno, estuvo en el foco de atención del gobierno. Se determinó que, en adelante, -conforme a la moral de la Iglesia Católica Apostólica Romana-, deberían contar con la autorización del Inspector General para su funcionamiento dentro del territorio de la provincia previa "justificaciones necesarias sobre la moralidad, religión y suficiencia". ${ }^{23}$ Nuevamente se dejó como única fuente de financiamiento para las escuelas de la campaña los ingresos obtenidos de los corrales de abasto. Además, se decretó que no se debía exigir a los padres indigentes que sus hijos cumplieran con la instrucción escolar. Los fondos públicos se destinaron principalmente al mantenimiento de los gastos militares - producto de la urgencia que marcaba el estado de guerra que se vivió durante el régimen rosista- y para el clero que

\footnotetext{
${ }^{21}$ Así se decretó que: “...Las escuelas de niñas se establecerán por la Sociedad de Beneficencia, quedando bajo su dirección e inspección, en la misma forma que lo están las escuela de la capital. Archivo Histórico de la Provincia de Buenos Aires (en adelante AHPBA). Registro Oficial. Libro 4. Recopilación de leyes y decretos 1810-1835, 26 de abril de 1826.

${ }^{22}$ Entre los requisitos exigidos a los profesores de primeras letras -en su mayoría de origen inmigrante en estos años- se establecía que debían acreditar previamente su moralidad ante el Vicerrector inspector de las escuelas y su inteligencia ante el Director General de dichas escuelas. Ver: AHPBA, Registro Oficial. Libro 4. Recopilación de leyes y decretos 1810-1835, 14 de junio de 1826.

${ }^{23}$ Archivo General de la Nación: Sala X-17-6-3.
} 
debía difundir el sermón patriótico-federal. Esa restricción de fondos llevó a que se cerrara la Casa de Expósitos y se suprimieran el pago de sueldos a maestros y todo tipo de gastos de escuelas. ${ }^{24}$ La suerte de las escuelas de la campaña -incluso las escuelas de niñas que estaban bajo la gestión de las Damas de la Sociedad de Beneficencia- quedó librada a los esfuerzos de los pobladores de la campaña. Además, se otorgó el contralor de las escuelas y de su personal docente al Jefe de Policía, reduciendo claramente la injerencia del Inspector de Escuelas.

Después de la derrota en Caseros de Rosas en 1852 parecía que, en materia de instrucción, quedaba todo por hacer. Según se aducía, se debía retomarse el rumbo trazado durante los años veinte. Una de las primeras medidas fue avanzar en la centralización administrativa creando el Departamento de Escuelas, designándose en cargo máximo a Domingo Faustino Sarmiento. En su cargo de Jefe del Departamento de Escuelas consiguió que se sancionara la Ley de fondos propios para el funcionamiento de las escuelas en 1858. En ese año comenzó a publicarse los Anales de la educación común. La publicación perseguía como objetivo promover los beneficios de la educación y, en particular, del modelo de escolarización pública.

Fue una etapa donde las fuentes de conflicto se renovaron, más allá de la convicción compartida de extender la alfabetización. Así, por ejemplo, a pesar de la intención de Sarmiento de fomentar la instrucción laica, los curas continuaron con su injerencia en materia educativa. Fueron parte de ese conjunto de personajes de los pueblos de la campaña con reconocimiento público convocados para formar parte de las comisiones municipales de educación, de las comisiones evaluadoras o enseñando la doctrina religiosa en las escuelas. ${ }^{25}$ La lábil presencia de los gobiernos nacionales y provinciales de los años anteriores había contribuido a reforzar las prácticas comunales que permitieron la acción de los personajes "notables". ${ }^{26}$ De allí que, molestara la impronta de la gestión de Sarmiento, inspirado en las renovadas propuestas pedagógicas de Horace y Mary Mann que lo llevaron -incluso- a traer maestras normalistas norteamericanas para formar al nuevo elenco del magisterio. ${ }^{27}$

Los preceptores y maestras de aquellas escuelas tuvieron que batallar incansablemente para ganarse la confianza de los padres de familia y el respeto de los vecinos. Así como la escuela fue cuestionada porque transmitía saberes

\footnotetext{
${ }^{24}$ AHPBA, Registro Oficial. Libro 4. Recopilación de leyes y decretos 1810-1835, 12 junio 1835.

${ }^{25}$ En aquellos años llegan al país numerosas congregaciones religiosas provenientes de Europa que fundan colegios y hospitales. Ver: ZANATTA, Loris y Di STEFANO, Roberto Historia de la Iglesia Argentina. Desde la Conquista hasta fines del siglo XX, Grijalbo, Buenos Aires, 2000. Un aporte que recupera esa presencia de los curas en las comunidades de la campaña bonaerense en la segunda mitad del siglo XIX es el de: BILBAO, Lucas "'Gringos' en la frontera: los curas del Tandil y el Azul en la segunda mitad del siglo XIX", Revista Folia Histórica del Nordeste, Instituto de Investigaciones Geohistóricas (Conicet-UNNE) e Instituto de Historia, Facultad de Humanidades (UNNE), 2015, pp.243-264.

${ }^{26}$ Un trabajo muy sugerente que recoge la trayectoria del inmigrante danés Juan Fugl en materia educativa en Tandil (sudeste de la provincia de Buenos Aires), que contó con ciertas ventajas comparativas en un contexto signado por el analfabetismo, es el de: BJERG, María Mónica El mundo de Dorotea. La vida en un pueblo de la frontera de Buenos Aires en el Siglo XIX, Imago Mundi, Buenos Aires, 2004.

${ }^{27}$ Esa intención de promover la renovación pedagógica abrió otro frente de tensión con las Damas de la Sociedad de las Beneficencia y sus métodos de enseñanza. Al respecto consultar: LIONETTI, Lucía "Las Damas de la Sociedad de Beneficencia educan a las hijas de la campaña bonaerense (1852-1875)", en OBINO WERLE, Flavia La educación rural en América Latina siglo XIX y XX, Liber Libros, Brasilia, 2010, pp. 172-195.
} 
que poco tenían que ver con su suerte futura, también los maestros fueron criticados por interferir con la autoridad de los padres. Sin embargo, no dejaron de acudir a la prensa local para publicar avisos donde se invitaba a los padres para que llevaran a sus hijos a las escuelas. ${ }^{28} \mathrm{O}$ para reclamar que, "debían servirse de enviarlos con puntualidad al toque de la campana" ${ }^{29}$

Los y las lectoras sabrán disculpar este breve recorrido, donde no se da cuenta de los matices y de los conflictos en toda su densidad por cuestiones de espacio y porque no es el propósito de este escrito. Solo a modo de síntesis puede afirmarse que, la inestable presencia de las autoridades estatales, las muchas veces cuestionada figura de los preceptores y el peso del entramado social y político de las comunidades hizo azarosa y, a veces, errática la presencia de esas escuelas de primeras letras. La presión de figuras notables de las comunidades -como curas y jueces de paz-, impuso condicionamientos a las decisiones de las autoridades de turno. La escuela y sus preceptores, participaron de una suerte de teatro social, donde los distintos actores dieron cuenta de su capacidad de agencia para resistir, mediar y negociar. De allí que, resulta válido pensar en el lugar que ocupó esa escolarización a la hora de rastrear ese proceso de configuración del poder estatal y su relación con la sociedad civil.

Un punto de inflexión se concretó cuando el Gobierno de la Provincia de Buenos Aires -durante la segunda gestión de Sarmiento como Director del Departamento de Escuelas- sancionó la Ley de Educación Común, gratuita y obligatoria en 1875, una normativa que, por otra parte, garantizó la enseñanza religiosa en las aulas. La sanción de esta Ley otorgó, por lo menos en la letra, una gran responsabilidad a la sociedad civil al entregarle el control educativo a través de los Consejos Escolares, compuestos por vecinos elegidos por sus propias comunidades. Sin embargo, para muchos, esta ley implicó limitar su campo de acción al imponer un modelo educativo que dejaba poco margen para las iniciativas locales concretas que antaño habían existido más allá de la "ficción" democrática que suponía que los vecinos elegían a sus representantes en los concejos escolares. Para otros, lo inacabado de la tarea, frente a los magros resultados que se exponían en los informes sobre índices de alfabetización, exigía una mayor presencia del Estado. Aquella fue una razón que esgrimió el Estado Nacional al sancionar la Ley de Educación común, gradual, gratuita, obligatoria -sobre la que se asentó la tradición laica de nuestras escuelas- en 1884.

Más allá de esos debates, la realidad mostró que el alcance de las políticas alfabetizadora, instauradas desde los sistemas estatalistas de la nación y las provincias, siempre fue objeto de críticas por lo inacabado de la tarea. Es más, el propio Estado nacional sancionó la Ley Láinez en 1905 tratando de cubrir ese déficit escolar que las provincias generaban pero, como sea, aún bien entrado el siglo XX, fue necesario el auxilio de las iniciativas particulares, donde la Iglesia

\footnotetext{
${ }^{28}$ Se encuentran avisos como los siguientes: "Escuela de Canchillo. El que suscribe avisa que la escuela está abierta para todos los niños del distrito, desde las 9 de la mañana hasta las dos de la tarde. Enseñanza gratis. Tomás D’Ambra". El Monitor de la Campaña, Año I, núm. 2, 3 de julio de 1871. Este periódico fue publicado en la comunidad de Capilla del Señor Exaltación de la Cruz (entre 1871-1873) y su Director fue Preceptor y Director de la Escuela Urbana Elemental ubicada en la Plaza de la Concordia. Según se le reconocía, gracias a su iniciativa, se fundó la primera biblioteca popular de la campaña y el periódico que fue el primero de la campaña.

${ }^{29}$ El Monitor de la Campaña Bonaerense, Año I, núm. 4, 17 de julio de 1871.
} 
Católica e instituciones como la Sociedad de Beneficencia tuvieron un especial protagonismo, sobre todo, con lo que se definía como la niñez desvalida. ${ }^{30}$

\section{La presencia y las experiencias de la niñez en la campaña bonaerense}

En ese errático itinerario de investigación surgió recurrentemente un interrogante más que elemental: ¿Cómo fue la experiencia de ser niño/niña en el marco de ese escenario social? En los archivos trabajados para el caso de la escolarización aparece una referencia esquiva en ese sentido. ${ }^{31}$ Obviamente, la niñez era el centro de interés y preocupación de esas acciones en torno a la escolarización pero, escasamente puede encontrarse referencias que nos aproximen a su mundo cotidiano y al lugar que ocupaba dentro de las familias y la comunidad. En esa dirección, una vez más, las fuentes judiciales resultan extraordinariamente valiosas porque nos acercan -más allá de las evidentes mediaciones- a esas experiencias de niños y jóvenes en el contexto de la campaña bonaerense entre los siglos XVIII al XIX. ${ }^{32}$ Ya se ha advertido que muestran un recorte fugaz y circunstancial de la vida de los sujetos sociales que quedaron involucrados pero que, sin embargo, permiten aproximarse a un universo de valores y un sentido del orden en ese contexto. Así, se han hallado hechos, sucesos o situaciones en las que quedaron involucrados involuntariamente niños, niñas y jóvenes, dando cuenta de una subalternidad atravesada por el origen social, el género y la edad.

Fuentes ricas y complejas, que como lo expresaron, en sus pioneros trabajos, Mayo, Mallo y Barreneche evocaron el conflicto, la ruptura y el mundo de valores que sustentan la trama social. ${ }^{33} \mathrm{Al}$ ventilar sus discrepancias ante la justicia, los litigantes o sus letrados desnudaron de manera indirecta el marco normativo que fue quebrado, el orden anhelado, las pautas de equilibrio y del consenso perdido. Este tipo de fuentes, que nos acerca a esos recortes de la vida cotidiana, nos revelan en las mediaciones de las palabras de quienes denuncian, los denunciados, los testigos y las propias autoridades judiciales un registro de

\footnotetext{
${ }^{30}$ Estas cuestiones fueron trabajadas oportunamente, solo por cuestiones de espacio citamos: LIONETTI, Lucía La misión política de la escuela pública: construir al ciudadano de la república, Ediciones Miño y Dávila, Buenos Aires, 2007. Un aporte donde se analiza los medianos alcances de la escolarización pública en la provincia de Buenos Aires en la primera mitad del siglo XX y la impronta refundante del gobierno de Mercante durante el peronismo es el de: PETITTI, Mara Más allá de una escuela peronista. Políticas públicas y educación en la provincia de Buenos Aires (19461955), en prensa .No podemos entrar a explicar los pormenores de los matices de las políticas públicas implementadas sobre ese universo de niños y "menores" desvalidos, donde intervinieron instituciones de la sociedad civil pero, solo a modo de ejemplo, podemos citar un trabajo donde se muestra la tarea en la que se abocaron las damas de la elite en el sudeste de la provincia de Buenos Aires: de PAZ TRUEBA, Yolanda Mujeres y esfera pública: La campaña bonaerense entre 1880 y 1910, Prohistoria, Rosario, 2010.

${ }^{31}$ El desarrollo del joven campo de los estudios sobre y de la infancia en Argentina trabajo fue el resultado de un profuso trabajo y diálogo entre distintas disciplinas como la antropología, la historia, la sociología, el derecho, la psicología, los estudios culturales y literarios, las ciencias de la educación y la historia de la educación. Al respecto ver: COSSE, Isabella - LLOBET, Valeria VILLALTA, Carla y ZAPIOLA, Ma. Carolina (comp.) Infancias: politicas y saberes en Argentina y América Latina (siglos XIX y XX), Teseo, Buenos Aires, 2011.

${ }^{32}$ Un trabajo donde se plantea esta cuestión para el caso de América Latina es el de: ROJKIND, Inés y SOSENSKI, Susana "Los niños como actores sociales en la historia de América Latina (siglos XIX y XX) en Trashumante. Revista Americana de Historia Social, núm. 8, 2016.

${ }_{33}$ MAYO, Carlos - BARRENECHE, Osvaldo y MALLO, Silvia Frontera, sociedad y justicia coloniales, UNLP-FaHCE, La Plata, 1989, Disponible en:

htp/ / www.memoria.fahce.unlp.edu.ar/libros/pm.66/pm.66.pdf
} 
las emociones, de quiebres de expectativas y de conflictos que se ventilaron en ese acto público que colocó como protagonistas de primer rango a esa niñez.

Dentro de ese universo de causas en la que aparece esta subalternidad, tal como en su momento advirtió Pablo Cowen, el estupro de las niñas y jóvenes constituyó un capítulo importante. Es altamente probable que haya habido muchos otros delitos que la justicia no constató debido a que no existió denuncia pública y que en consecuencia han escapado a nuestra consideración. Algunos de ellos, habrían sido casos habituales, como el abandono de recién nacidos en la calle, y muchos casos de violación, abusos en distintas manifestaciones, alcoholismo, etc., que no eran denunciados para evitar el escándalo público, por desconocer los intervinientes los mecanismos de la justicia o porque esta era inaccesible a los requerimientos de las víctimas. ${ }^{34}$

En el caso de nuestro trabajo, hasta aquí, hemos podemos recuperar esas dolorosas experiencias de modo particular para el caso de las niñas desde la segunda mitad del siglo XVIII. Precisamente las fuentes judiciales $-y$ en este caso en particular los expedientes de la justicia del crimen de Buenos Airespermiten recuperar esas historias mínimas, recortes de vidas de la cual desconocemos su pasado y su futuro. Aproximaciones de un presente en los que quedaron involucradas algunas niñas en diversos incidentes que las tuvo como protagonistas involuntarios y que dan cuenta de los modos de vida, de un sentido del orden, moral y de justicia en aquel contexto y de la consideración que recibía la niñez. ${ }^{35}$

Esto implica reconocer las precauciones metodológicas que deben tenerse al acercarse a este tipo de fuentes porque sabemos que esas palabras registradas, esas denuncias y acusaciones -así como los argumentos expuestos por cada uno de los declarantes- están tamizados por el estricto acto judicial que cumple el funcionario de turno. La propia naturaleza de este tipo de registro documental nos acerca a un evento conflictivo, y a través de él, a un mundo social, con normas, expectativas y pautas de comportamiento. Atendiendo esas posibilidades y claro está las limitaciones, la intención de abordar este tipo de conflictos que trascendían el espacio familiar e involucraban a los vecinos es la de comprender cuál era el lugar que ocuparon niños, niñas y jóvenes en ese orden social.

En este caso, no es posible explayarnos sobre algunos de esos expedientes pero si se puede afirmar que, un presupuesto del cual se parte a la hora de abordarlos es que, la cuestión de la niñez -en aquella sociedad como en cualquier otra- estaba estrechamente relacionada con las formas de ejercicio del poder -no solo en su relación con los adultos sino también, en relación a lo político. Desde ese punto de visto, como explica Lorandi si se entiende al poder como ese complejo entramado donde se cruzan la sociedad y la cultura, implica conocer de cada sociedad que se estudia la estructura, las normas y

\footnotetext{
${ }^{34}$ COWEN, Pablo "La infancia porteña a través de las Fuentes Judiciales. Fines del siglo XVIII primeras décadas del siglo XIX", en Justicia y Sociedad Colonial. La Fuente Judicial en la Construcción de la Memoria. Suprema Corte de Justicia, Universidad Nacional de Mar del Plata, 1999 , p.74.

${ }^{35}$ En relación a la consideración jurídica de los menores, la antigua legislación castellana y aquella ratificada o producida en la etapa posrevolucionaria, determinaba que, salvo circunstancias especiales, debía distinguirse entre los menores a los púberes y a los impúberes, siendo los catorce años la edad que se establecía para tal división. Esa minoridad implicaba una naturaleza incompleta, una incapacidad que debería suplirse por la presencia de un padre, tutor o curador, un protector de un ser que revertirá su incapacidad, por la maduración y crecimiento del "buen juicio".
} 
comportamientos sociales que sustentan, por un lado, las instituciones -tanto formales como informales- y, por otro, definen las modalidades de acción y coerción que se adoptan persiguiendo el bienestar colectivo.

Una vez más, al transitar los expedientes encontramos que la vecindad era fundamental para comprender el tenor y el peso de los testimonios. Fue otro modo de constatar lo que señalaron Fradkin y Garavaglia cuando explicaron que, el término "vecino", no devenía de una norma legal que prescribiera con precisión los atributos que había que reunir para acceder a ella sino que era una categoría social con implicancias legales y jurídicas y expresaba los lazos sociales de integración, lealtad e identificación con una comunidad. Era a una condición a la que se accedía por reconocimiento. ${ }^{36}$

Para bucear por este tipo de archivos fue necesario leer en otra clave esos aportes así como, conocer más de cerca la estructura, la organización, el funcionamiento del sistema judicial y a quiénes administraban justicia, de qué manera lo hacían y con qué resultados. Con el fin de intentar una reflexión histórica acerca del modo en que se vivenció y se pensó la justicia en el mundo occidental, se retomó el planteo de Prodi quien argumenta que, en la historia de la civilización cristiana occidental, el nodo medular para comprender el nacimiento del Estado de derecho y del ideal liberal es la progresiva distinción entre el concepto de pecado, como desobediencia a la ley moral, y el concepto de delito, como desobediencia a la ley positiva. Es necesario entrar a la vida concreta del fuero, ante el cual se convoca al hombre a responder por sus acciones. ${ }^{37}$

El peso de esa tradición moral se denota claramente en la concepción particular de justicia que trajeron los españoles a las colonias americanas. La función de administrar justicia no fue encomendada a un grupo especial de funcionarios, o lo que hoy llamaríamos un poder del Estado, sino que prácticamente todos los funcionarios del gobierno indiano tuvieron, en mayor $\mathrm{o}$ menor medida, la facultad de poder ejercerla. No existió división de poderes pero si de funciones, así se distinguieron las funciones de gobierno, justicia, guerra y hacienda que gozaban de una relativa autonomía.

Desde el Rey -que obtenía su función jurisdiccional de Dios- abajo, todos estuvieron revestidos del poder que se ejercía en su nombre. Pero ese poder real que no reconocía límites sobre la tierra, no era absoluto porque se limitaba su autoridad por la ley, por los fueros, por la religión, el Derecho natural y por la armazón misma de la monarquía a la que pertenecía. De él derivaba la potestad jurisdiccional de los funcionarios encargados de administrar justicia en el Imperio.

Esa administración de justicia era ejercida por jueces capitulares, jueces reales, jueces eclesiásticos y jueces que integraban el sistema de la Audiencia. De modo particular, los casos que me encuentro trabajando estuvieron bajo la competencia de los jueces capitulares que eran los que formaban parte del Cabildo, o bien recibían el nombramiento de ese cuerpo. Eran los Alcaldes de la santa hermandad que no necesitaban ser letrados, sus cargos eran electivos y duraban un año y no podían ser reelegidos salvo con un intervalo de dos.

\footnotetext{
${ }^{36}$ FRADKIN, Raúl y GARAVAGLIA, Juan Carlos La Argentina colonial. El Río de la Plata entre los siglos XVI y XIX, Siglo XXI, Buenos Aires, 2009, p.135.

${ }^{37}$ PRODI, Paolo Una historia de la justicia. De la pluralidad de fueros al dualismo moderno entre conciencia y derecho, Katz, Madrid, 2008. Aquí el autor retoma el aporte de: CLAVERO, Bartolomé "Delito y pecado. Noción y escala de transgresiones", en TOMÁS Y VALIENTE, Francisco et al. Sexo barroco y otras transgresiones premodernas, Alianza, Madrid, 1990.
} 
Actuaban "a costas", es decir que, las partes del litigio debían abonar sus honorarios y no recibían sueldo de la Corona. Su justicia era inminentemente localista, por su origen y por su desempeño, imbuida de todas las preocupaciones políticas, religiosas y sociales que tanto predominio ejercían en aquellas comunidades incipientes, quitando así a los alcaldes gran parte de su independencia y su imparcialidad. Entendían en los denominados "delitos de hermandad" que se cometían fuera de la ciudad, en lugares despoblados; salteamientos de caminos, muertes y heridas, incendios de campos, violación de mujeres, robos y hurtos y otros más que las leyes indicaban. Revestían las mismas características que los alcaldes ordinarios y desempeñaban además de estas funciones, otras de carácter administrativo.

Era una figura jurisdiccional de baja justicia que formó parte de ese grupo de agentes que participó del proceso de equipamiento político del territorio. Además de administrar justicia sumaria, realizaban actividades que podrían encuadrarse en la de producción de normativa: los alcaldes de la hermandad de los cabildos de Buenos Aires y de Luján- entre otros- dictaban "autos de buen gobierno" donde caracterizaban con mucha precisión a las "personas de mal vivir". ${ }^{38}$

El trabajo de un historiador sensible como Juan Carlos Garavaglia fue clave a la hora de pensar las conexiones entre la forma de hacer justicia y el tipo de sociedad donde se ejercía. ${ }^{39}$ Sus aportes, junto a otra notable producción, ${ }^{40}$ permiten reconstruir -atendiendo esa premisa- el cambio de la figura de alcalde de la hermandad, que desapareció con los cabildos, por la de Juez de Paz. ${ }^{41}$

\footnotetext{
${ }^{38}$ Cfr. BARRIERA, Darío "Justicias rurales: el oficio de alcalde de la hermandad entre el derecho, la historia y la historiografía (Santa Fe, Gobernación del Río de la Plata, siglos XVII a XIX)", en Andes, Salta, vol. 24, 2013, pp. 1-33.

${ }^{39}$ Entre otros aportes de Garavaglia para esta cuestión, en este caso, fue nodal la lectura de:

"Alcaldes de la Hermandad et Jugues de Paix a Buenos Aires (XVIIIe-XIXe siecle)", en Études Rurales, núm. 140-150, enero-junio, 1999; Poder, conflicto y relaciones sociales..., cit. Para saber que las instancias de mediaciones de los alcaldes de la santa hermandad, muchas veces evitaba que no llegara a la sumaria escrita, fue valioso su apreciado trabajo sobre San Antonio de Areco (16801880). Un pueblo de la campaña, del Antiguo Régimen a la "modernidad" argentina, Prohistoria, Rosario, 2009.
}

${ }^{40}$ De esa vasta producción, por límites de espacio nos remitimos a citar a: BANZATO, Guillermo y VALENCIA, Marta "Los jueces de paz y la tierra en la frontera bonaerense, 18201885", en Anuario IEHS, núm. 20, Tandil, 2005, pp. 211-237; BARRIERA, Darío G. "Justicias, jueces y culturas jurídicas en el siglo XIX rioplatense", en Nuevo Mundo Mundos Nuevos, 2010, disponible en:

http:// nuevomundo.revues.org/59252; FRADKIN, Raúl (comp.) El poder y la vara. Estudios sobre la justicia y la construcción del Estado en el Buenos Aires rural, Prometeo, Buenos Aires, 2007. FRADKIN, Raúl (comp.) La ley es tela de araña. Ley, justicia y sociedad rural en Buenos Aires, Prometeo, Buenos Aires, 2009; GELMAN, Jorge "Justice, état et societé. Le rétablesment de l'ordre a Buenos Aires apres l'indépendence (1810)", en Étude Rurale, núm. 149-150, enero-junio 2000, pp. 11-124; GELMAN, Jorge "Crisis y reconstrucción del orden en la campaña de Buenos Aires. Estado y sociedad en la primera mitad del siglo XIX", Boletín del Instituto de Historia Argentina y Americana Dr. Emilio Ravignani, núm. 21, $3^{\circ}$ serie, Primer Semestre 2000, pp. 7-31; TÍO VALLEJO, Gabriela "Los historiadores hacen justicia. un atajo hacia la sociedad y el poder en la campaña rioplatense en la primera mitad del siglo XIX", en Revista de Historia del Derecho, núm. 41, Buenos Aires, enero-junio 2011, pp. 199-212; YANGILEVICH, Melina "La justicia de paz en la construcción estatal al sur del Río Salado (Buenos Aires, primera mitad del siglo XIX), en PIAZZI, Carolina (ed.) Modos de hacer justicia. Agentes, normas prácticas, Prohistoria, Rosario, 2011.

${ }^{41}$ Barriera, citando a Sanjurjo, explica que, "Justicias de paz" es el nombre genérico que recibe en casi todo el mundo "las justicias de equidad". Como reflexiona: "Las justicias de equidad funcionaron -me atrevo a decir que en todos los territorios de tradición hispánica- como un puente entre las culturas jurisdiccionalista y constitucionalista. Es más, nos permite ver 
En lo que se refiere al trayecto de mi investigación recién se están transcribiendo unos pocos expedientes de las primeras décadas del siglo XIX donde aparecen los registros de esa niñez, con lo cual queda un trabajo de largo aliento en los archivos judiciales y de lectura de ese valorado aporte que se ha realizado sobre las formas de hacer justicia en la campaña bonaerense.

\section{Palabras finales}

Cerramos este escrito con la misma sensación que comenzamos, no está a la altura de lo que se pretendía decir acerca de lo que ha significado Juan Carlos para quienes tuvimos la fortuna de conocerlo y valorar su estatura como Hombre, Maestro e Historiador. Faltan las palabras porque se ven rebasadas por su fuerte presencia, una presencia que nunca será ausencia. Seguirá siendo una guía cada vez que recordemos sus palabras, sus consejos, sus acciones. Cada vez que leamos sus trabajos porque nos sigue guiando en esa senda que trazó de exquisito historiador.

Por tu afecto, por tus enseñanzas, por tus palabras, por tu sabiduría: querido Juan Carlos simplemente GRACIAS. La tristeza cede y me permite celebrar el día que me atreví a estudiar el Profesorado y la Licenciatura de Historia en la UNICEN, fue esa oportunidad que me dio la vida para conocerte.

Tandil, diciembre de 2017.

justamente uno de los senderos por los que transitó el pasaje -que fue lento y como un oleaje, con idas y vueltas- de una cultura basada en un orden trascendente y la ley como elemento indisponible a otra donde la ley es elaboración política de los hombres. También permite advertir la lentitud de los cambios entre una vecindad cuyo atributo de pertenencia se basaba a ser parte de una comunidad confesional a otra donde la pertenencia a una comunidad política no pasaba por la confesión religiosa sino por la confraternización política alrededor de un pueblo, una provincia, o más tarde, de un identificador interregional promovido como nación." BARRIERA, Darío "¿Qué nos enseña la historia de las instituciones judiciales? Algunos apuntes sobre la lenta historia de la separación de funciones" en, BANDIERI, Susana - FERNANDEZ, Sandra (coord.) La historia Argentina en perspectiva local y regional. Nuevas miradas para viejos problemas, Tomo 2, Teseo, Buenos Aires, 2017, pp.133-156. Una reflexión que, otra vez, nos hace pensar en el lugar de la escuela en ese lento pasaje y de la niñez en su tránsito a la infancia considerada como los "futuros ciudadanos de la república". 